\title{
A Study on Thermal Behavior Properties of Purslane Leaves Using Different Drying Techniques
}

\section{N Nandini ${ }^{1 *}$, B Mounika ${ }^{1}$, Tasleem ${ }^{1}$, V Bhasker ${ }^{2}$ and P Prashanth ${ }^{1}$}

${ }^{1}$ M. Tech Food Technology, Department of Food Technology University College of Technology, Osmania University, Osmania University Hyderabad, Telangana, India

${ }^{2}$ Assistant Professor, Food Technology, Department of Food Technology University College of Technology, Osmania University Hyderabad, Telangana, India

*Corresponding Author: N Nandini, M. Tech Food Technology, Department of Food Technology University College of Technology, Osmania University, Osmania University Hyderabad, Telangana, India.

Received: August 08, 2019; Published: September 20, 2019

DOI: 10.31080/ASAG.2019.03.0653

\section{Abstract}

Drying is one of the major process utilized for the preservation of agricultural products. Several types of drying methods are known to dry different agricultural products with its own advantages and limitations. Choosing the right drying system is thus important in the process of drying agricultural products. Proper care is required in choosing the drying system. It is important to compare traditional and other drying methods for the reduction of the drying time and for the improvement of product quality. Drying helps in minimizing the possibilities of the contamination caused by insects and microorganisms thereby preserving the product.

The drying characteristics of Purslane leaves were obtained using tray drier and infrared dryer. The drying profile of purslane leaves was determined in the two drying systems by monitoring moisture loss over the drying period. Changes in time, yield were assessed. The rate of moisture removal during infrared drying was faster than tray drying. Yield is higher in infrared heater than tray drying.

Keywords: Drying; Yield; Agricultural Products; Purslane

\section{Introduction}

Purslane (Portulaca oleracea L) is a common weed seen in turf grass areas and field crops. Many varieties of purslane are cultivated in a wide range of climates and regions. It is used in combination with various foods. Purslane is observed to be a better nutritional crop and is regarded as a power food having higher amount of beta-carotene, ascorbic acid, and alpha-linolenic acid.

Purslane an invasive weed, is a wild growing succulent delicious edible plant. It is also called as hogweed, verdolaga, and adds a slightly tangy taste to soups and fries, and its leaves can be used to add better texture to various salad types. Purslane is an all-round healthy food that contains a whole wide range of health promoting nutrients such as omega-3 fatty acids, antioxidant vitamins, and minerals.

Purslane is one of the best vegetable source omega- 3 fatty acids It is rich in minerals such as calcium and magnesium which are crucial for keeping bones, teeth and muscles healthy. It is also a good source for potassium, thus helping to keep blood pressure in check. Eating purslane aids in additional iron supplement, a mineral that is essential for oxygen transport within your body.
The process of drying helps in removal of moisture from a substance. Drying is regarded as oldest, commonly used and energy consuming unit operation for food preservation. The demand for high-quality dried products is increasing all over the world. It is one of the complicated process since it involves simultaneous mass and heat transfer, particularly under transient conditions.

The main purposes of drying are

- $\quad$ To prevent (or inhibit) microorganisms.

- $\quad$ To increase shelf life.

- To ease the handling, storage and transport of products.

- To prepare the product to subsequent processes.

Tray dryers function in batch mode, use series of racks to hold product and circulate air over the material. Hot air circulates through the tunnel over the racks. These types of dryers are useful when the rate of production is small. They are used to dry a range of materials, but are labor intensive and are expensive to operate. They are frequently used for drying valuable products. Drying operation is slow and uses hours to complete drying of a single batch. 


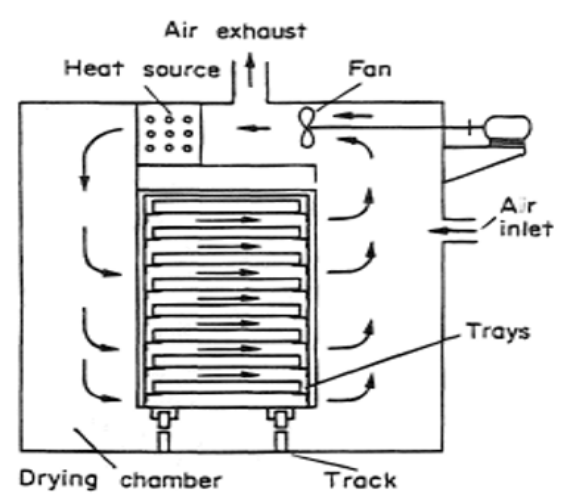

Figure 1: Schematic diagram of Tray drier.

Flameless Catalytic Infrared Energy (FCIR) is generated by catalyzing natural gas or propane with a proprietary enhanced platinum catalyst. Natural gas is combined with air across the platinum catalyst and reacts by oxidation-reduction to produce a controlled bandwidth of infrared energy and minimal amounts of $\mathrm{CO} 2$ and water vapor. The important aspect to this process is that the bulk of the radiant energy bandwidth generated is in the "far infrared" range, with wavelengths in the range of 3 to 7 microns. Water rapidly absorbs the infrared radiant energy at 3, 4.5 and 6 microns wavelength. The energy delivered by Catalytic Drying Technology (CDT)'s flameless catalytic infrared system perfectly targets the moisture in the substrate. Absorption of infrared energy is directly proportional to the products moisture content.

\section{Materials and Methods}

\section{Tray drying of purslane}

Drying experiments were carried out in a tray drier. The samples of the purslane (stems+ leaves) weighing about $500 \pm 0.5 \mathrm{~g}$ were spread on the tray. The drying experiments were conducted at 50,60 and $70^{\circ} \mathrm{C}$. Initial weight of the tray and sample was noted. During drying process, the tray was weighed at $30 \mathrm{~min}$ intervals. Then, the dried samples were packed into aluminum covers, which were then heat-sealed and stored at ambient temperature.

\section{Infrared drying of purslane}

Drying experiments were carried out in a infrared heater. The samples of purslane (stem + leaves) weighing about 10 gm were spread evenly on the pan of moisture meter. The drying experiments were conducted at $50^{\circ} \mathrm{C}, 60^{\circ} \mathrm{C}$ and $70^{\circ} \mathrm{C}$. During drying process, the readings were taken at $5 \mathrm{~min}$ intervals.

Determination of moisture content:

Moisture content $(\%)=[($ Initial weight - Final weight $) \div($ Initial weight) $]^{*} 100$

\section{Determination of drying rate:}

(Initial weight - Final weight) $\div$ (Time interval)

\section{Results and Discussion}

Figure 2 represents the variations of moisture content (MC) with drying time for tray drying of purslane at 50,60 and $70^{\circ} \mathrm{C}$. It is evident that the moisture content decreases with drying time. The drying air temperature had a significant effect on the moisture content of samples. The rate of moisture loss was greater at higher temperatures, and the total drying time reduced substantially with the increase in temperature. The drying time reduced from 990 to $510 \mathrm{~min}$ when the air temperature is increased from $50^{\circ} \mathrm{C}$ to $60^{\circ} \mathrm{C}$ and the time reduced from $510 \mathrm{~min}$ to $270 \mathrm{~min}$ when the air temperature was increased from $60^{\circ} \mathrm{C}$ to $70^{\circ} \mathrm{C}$.

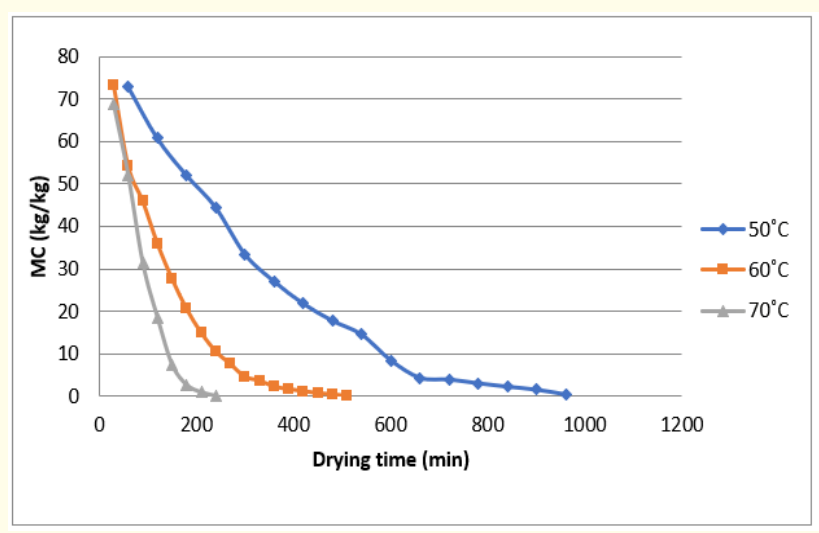

Figure 2: Variation of moisture content with drying time of purslane dried at different temperatures using Tray drier.

The drying rates defined as the quantity of water removed per unit time versus moisture content are shown in figure 3 . It is apparent that drying rate decreased continuously with moisture content. At the beginning of the drying process, drying rate was very high, and drying rate continued to decrease as moisture content approached to equilibrium moisture content. Constant drying rate period was not observed in the drying curves and the whole drying process take place in the falling rate period [1-10].

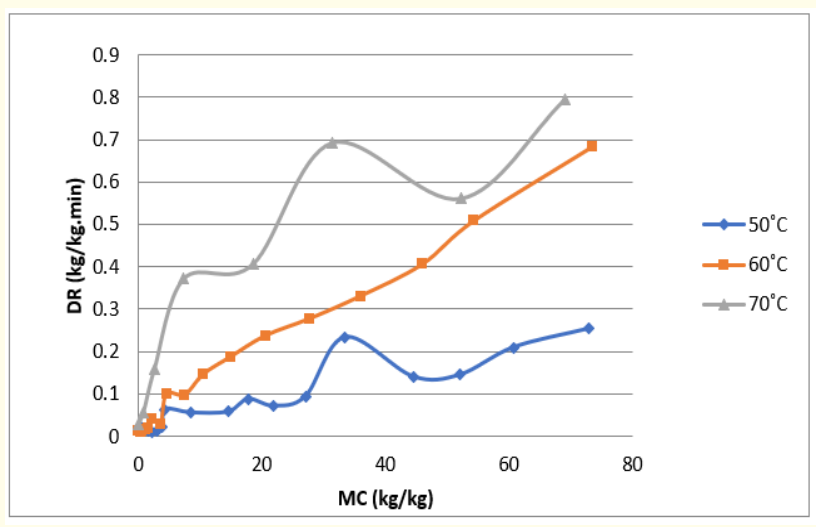

Figure 3: Drying rate with moisture content of purslane dried at different temperatures using Tray drier. 
Figure 4 represents the variations of moisture content (MC) with drying time for infrared drying of purslane at 50,60 and $70^{\circ} \mathrm{C}$. It is clear that the moisture content decreases continuously with drying time. Temperature had a significant effect on the moisture content of samples. The rate of moisture loss was greater at higher temperatures, and the total drying time reduced substantially with the increase in air temperature. The drying time was brought down from 100 to $60 \mathrm{~min}$ when the air temperature is increased from $60^{\circ} \mathrm{C}$ to $70^{\circ} \mathrm{C}$.

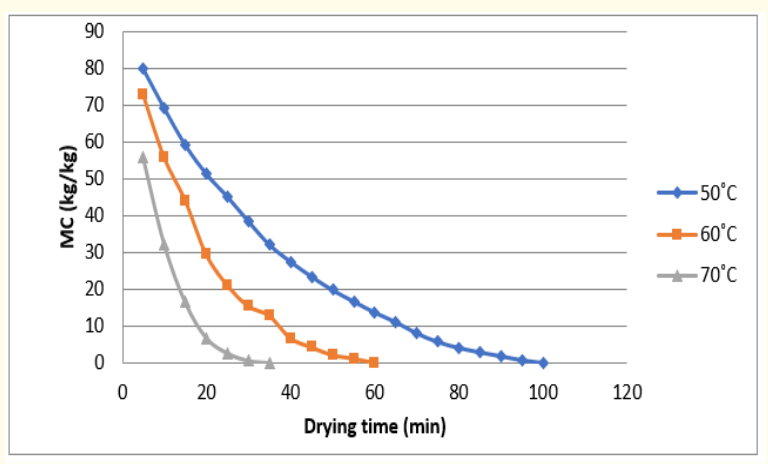

Figure 4: Moisture content with drying time of purslane dried at different temperatures using Infrared moisture meter.

The drying rates defined as the quantity of water removed per unit time versus moisture content are shown in figure 5. It is apparent that drying rate decreased continuously with moisture content. At the beginning of the drying process, drying rate was very high, and drying rate continued to decrease as moisture content approached to equilibrium moisture content. Constant drying rate period was not observed in the drying curves and the whole drying process take place in the falling drying rate period.

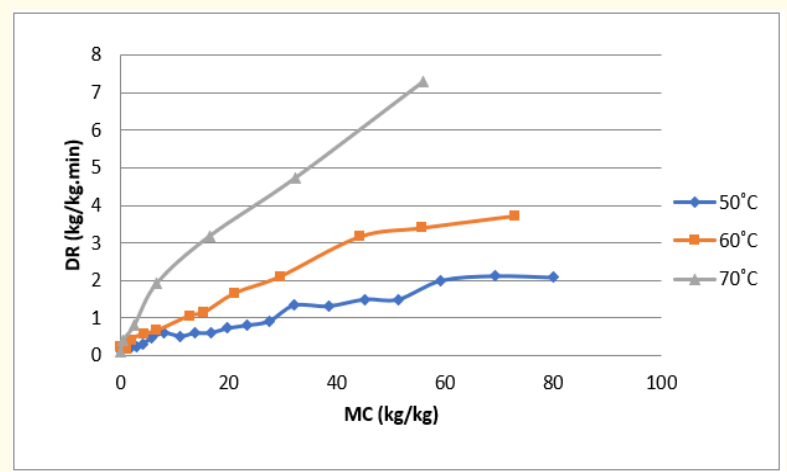

Figure 5: Variation of drying rate with moisture content of purslane dried at different temperatures using Infrared moisture meter.

\begin{tabular}{|l|c|c|c|}
\hline $\begin{array}{c}\text { Type of drying } \\
\text { at 50-C }\end{array}$ & $\begin{array}{c}\text { Time } \\
\text { (min) }\end{array}$ & $\begin{array}{c}\text { Moisture } \\
\text { removed (\%) }\end{array}$ & Yield (\%) \\
\hline Tray drying & 990 & 92.9 & 7 \\
\hline Infrared drying & 100 & 90.33 & 11.6 \\
\hline
\end{tabular}

Table 1: Comparison between Tray drier and Infrared drier at $50^{\circ} \mathrm{C}$.

\begin{tabular}{|l|c|c|c|}
\hline $\begin{array}{c}\text { Type of } \\
\text { drying at 60-C }\end{array}$ & $\begin{array}{c}\text { Time } \\
\text { (min) }\end{array}$ & $\begin{array}{c}\text { Moisture removed } \\
\text { (\%) }\end{array}$ & Yield (\%) \\
\hline Tray drying & 510 & 93.5 & 6.7 \\
\hline Infrared drying & 60 & 91.46 & 7.6 \\
\hline
\end{tabular}

Table 2: Comparison between Tray drier and Infrared drier at $60^{\circ} \mathrm{C}$.

\begin{tabular}{|l|c|c|c|}
\hline $\begin{array}{c}\text { Type of drying } \\
\text { at 70-C }\end{array}$ & $\begin{array}{c}\text { Time } \\
\text { (min) }\end{array}$ & $\begin{array}{c}\text { Moisture removed } \\
\text { (\%) }\end{array}$ & Yield (\%) \\
\hline Tray drying & 270 & 93.9 & 6.4 \\
\hline Infrared drying & 35 & 92.26 & 7 \\
\hline
\end{tabular}

Table 3: Comparison between Tray drier and Infrared drier at $70^{\circ} \mathrm{C}$.

\section{Conclusion}

- Infrared heating took lesser time for drying when compared to tray drying.

- Yield in Infrared heater is higher when compared to tray drier.

\section{Bibliography}

1. Ibrahim Doymaz. "Hot air drying of purslane (Portulaca oleracea L.)” (2013).

2. Derya Arslan. "Evaluation of drying methods with respect to drying kinetics, mineral content and color characteristics of rosemary leaves". In Energy Conversion and Management (2008).

3. Ibrahim Doymaz. "Thin layer drying of spinach leaves in a convective dryer" (2007).

4. J Ahmed., et al. "Drying characteristics and product quality of coriander leaves". Department of Food Science and Technology, Guru Nanak Dev University, India, (2001).

5. Li Y and Morey V. “Thin-layer drying rates and quality of cultivated American ginseng". Transactions of the ASAE 30 (1987): 842-847.

6. Lewicki PP., et al. "Effect of drying mode on drying kinetics of onion”. Drying Technology 16 (1998): 59-81. 
7. Md Kamal Uddin., et al. "Purslane Weed (Portulaca oleracea): A Prospective Plant Source of Nutrition, Omega-3 Fatty Acid, and Antioxidant attributes". The Scientific World Journal (2014).

8. Maria Gonnella., et al. "Purslane: A review of its Potential for Health and Agricultural aspects". A European Journal of Plant Science and Biotechnology (2010).

9. M Kashaninejad and L G Tabil. "Drying Characteristics of Purslane (Portulaca oleraceae L.)” (2007).

10. Rocha T., et al. "Effect of drying conditions and of blanching on drying kinetics of mint (MenthaspicataHuds.) and basil (Ocimumbasilicum)". In Drying '92; Mujumdar, A.S., Ed.; Elsevier Science (1992): 1360-1368.

\section{Volume 3 Issue 10 October 2019}

(C) All rights are reserved by $\mathbf{N}$ Nandini., et al. 